\title{
A hybrid charger of conductive and inductive modes for Electric Vehicles
}

\author{
Van-Binh Vu, Student Member, IEEE, José M. González-González, Volker Pickert, Member, \\ IEEE, Mohamed Dahidah, Senior Member, IEEE, and Alicia Triviño
}

\begin{abstract}
Electric Vehicles (EVs) are gaining more and more user acceptances due to their clean, efficient and environmentally friendly nature. Currently, most commercial EVs use conductive charging for their batteries. Inductive charging, which is an alternative charging technology, has recently received a great deal of attention because of its increased user convenience and safety. It is forecast that the two charging technologies will be implemented in future charging infrastructures globally. Consequently, future EVs need to be capable of dealing with both charging methods. So far, there has been only a very few charging topologies reported in the literature that describe both charging methods in the same vehicle. However, solutions that have been proposed do not show significant component reduction. This paper proposes a hybrid charger system where the high frequency transformer of an on-board DC-DC converter becomes the coupling point between conductive and inductive charging. Using this coupling point, the circuit utilizes the same components for conductive and for inductive charging. This results in the reduction of component count and therefore improved integration. The proposed system is verified by both simulation and experiment. For the experiment, a 3-kW prototype has been built and tested. A maximum efficiency of $97.4 \%$ and $93.6 \%$ was achieved in conductive and inductive mode, respectively.
\end{abstract}

Index Terms-Conductive charging, inductive charging, hybrid charger, electric vehicle, battery charger, coupler coils.

\section{INTRODUCTION}

$\mathrm{C}$ Yonductive charging is the most common method to charge Electric Vehicle (EV) batteries. A charger unit physically connects the EV battery to the power grid via a cable [1]. According to the international standard IEC 61851-1:2017 [2] conductive charging can be classified into four different modes: Mode 1 and 2 with Alternating Current (AC) and domestic sockets for low power, Mode 3 with AC and specific socket for high power and Mode 4 with Direct Current (DC for fast charging. While Modes 1,2 and 3 require an on-board charger in EVs, Mode 4 relies on an external charger. In North America, the standard SAE J1772 [3] is typically used to classify conductive chargers, with Level 1 and 2 for on-board AC charging and Level 3 for off-board DC charging. Many vehicle manufacturers include both AC and DC chargers in one vehicle enabling users to have more options to charge their vehicles at home or in public [4]. While off-board fast chargers provide

Van-Binh Vu, Volker Pickert and Mohamed Dahidah are with the School of Engineering, Newcastle University, Newcastle upon Tyne, NE1 7RU, UK (e-mail:v.b.vu2@ncl.ac.uk).

José M. González-González and Alicia Triviño are with Department of Electrical Engineering, University of Malaga, 29071 Málaga, Spain. direct DC currents into the battery, on-board chargers require the installation of all of the AC to DC power electronics inside the vehicle. On-board conductive chargers typically consist of a two-stage power converter, including a front-end $\mathrm{AC}-\mathrm{DC}$ converter and an isolated DC-DC converter with a high frequency transformer [5-8]. There are two common topologies for the DC-DC converter: full-bridge resonant (FBR) converters $[6,9,10]$ and phase-shift full bridge (PSFB) converters [11,12]. The FBR achieves high efficiency at fullload operation due to zero-voltage-switching (ZVS). Major drawbacks are that ZVS cannot always be achieved across the wide range of load and there are challenge in the design of high frequency transformers. The PSFB converter shows several desirable features such as simple control strategy, reduced component count and high-power density. However, PSFBs suffer from high-circulating current and hard-switching switches under light-load conditions.

Although conductive chargers are predominant in the current EV market, they have several disadvantages, such as the need for the user's intervention and safety issues. Inductive chargers are presented as a reliable alternative to solve part of these drawbacks [13-15]. However, inductive charging comes with its own challenges. The biggest challenge is to align the coils to gain high charging efficiency, although, recent advances in automation will enable parking aid systems to be integrated into the wireless charging process so that this shortcoming will be overcome [15, 34]. In the inductive charger, energy is transferred wirelessly from the grid side to the battery side by using time-varying magnetic fields. Due to the lower coupling coefficient between the transmitter and receiver coils, extra compensation circuits are indispensable parts in inductive charging systems. This contributes to an improvement in power transfer capability and overall efficiency [13]. The operating frequency is fixed at $85 \mathrm{kHz}$ in the standard SAE J2954 [17-18] for the inductive chargers. The most common structure includes an off-board front-end rectifier with power factor correction (PFC) and a full-bridge inverter powering the primary coil. The on-board secondary coil is connected to a passive or an active rectifier [19]. Power flow is controlled by the off-board fullbridge inverter. It is possible to control charging power within the vehicle by adding an on-board dc/dc converter between the on-board rectifier and the battery.

Conductive charging and inductive charging both have benefits over each other in certain contexts (i.e. efficiency or convenience). Thus, it is expected that both types of chargers will coexist simultaneously in the future EV market. This prevision leads to the need of hybrid EV chargers, which will be compatible with both charging methods [20]. By now, there 
are only very few solutions reported both commercially and academically. Commercially, Toyota and Tesla registered patents [21 and 22] of a hybrid charger. The basic charging structure is the same for both concepts by sharing the on-board DC/DC converter for both charging modes. Momentum Dynamics and Jaguar Land Rover [23], installed a 50-kW inductive charger system in the Jaguar I-PACE model for Cabonline, the largest taxi network in Norway. Jaguar vehicles already include an 11-kW three-phase on-board conductive charger. However, the conductive charger electronics components are not shared with the inductive charger due to the different power levels in both charger systems. The work in [24] discusses aftermarket conversion of inductive chargers in commercial EVs. There is no mentioning on how to share common power electronics between the conductive and the inductive chargers.

Academically, authors in [25] defined a hybrid solution that utilizes the integrated boost converter of the traction drive system to rectify the AC voltage of both, conductive and inductive chargers. The sharing of components between the two chargers however, is off-board and includes the grid rectifier, the high frequency (HF) full-bridge inverter and the transformer. The HF transformer can be connected to an onboard rectifier to allow conductive charging or to a pair of coupled coils for inductive charging. A 7.7-kW prototype was tested with $85.05 \%$ and $84,06 \%$ efficiencies for the inductive and the conductive charger, respectively. Similarly, [26] proposes a hybrid charger system in which the inductive and the conductive chargers share off-board components but not onboard components.

Regrettably, none of the commercial and academic published work describes in detail the hybrid charging methods from the original concept to analysis, design, implementation and experimental verification.

This paper proposes a hybrid charging structure to integrate a conductive charger (Mode 1 or 2) with an inductive charger based on magnetic coupling. The principal concept is shown in Fig. 1(a). It must be noted that inductive and conductive modes do not operate at one time. The key component of the proposed hybrid charger is composed of three different coils: one offboard coil and two on-board coils. In the conductive mode (CM), on-board coil 1 and 2 act as the primary and secondary coil, respectively as shown in Fig. 1(b). Both coils are electromagnetically coupled, working as a high-frequency isolation transformer for the conductive charger mode. The offboard coil is not activated in the conductive mode. On the other hand, in the inductive mode (IM) shown in Fig. 1(c), both onboard coil 1 and 2 acts as two separate receivers which simultaneously harvest power from the off-board coil. The advantage of the proposed systems is to maximize the sharing of the power electronics and the magnetic components between the two charging methods on the vehicle side. Therefore, all onboard charging systems are fully utilized in each mode reducing component counts and offering less space and complexity.

The paper is organized as follows. The circuit configuration and the coupler coils design of the proposed hybrid charger are presented in Section II. The design consideration and the implementation of the constant current/constant voltage battery charging are discussed in Section III. In Section IV, a 3-kW hybrid charger prototype is experimentally implemented to demonstrate the proposed system. Experimental results are provided to evaluate the performances of the proposed hybrid charger such as efficiency, output power and electromagnetic interference. Conclusion and future works are given in Section $\mathrm{V}$ to conclude the paper.

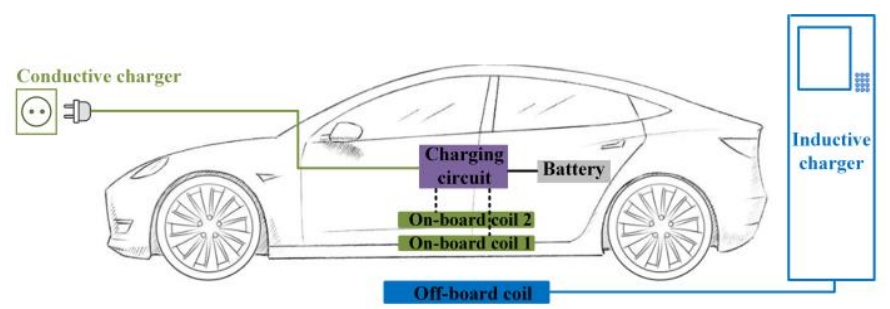

(a)

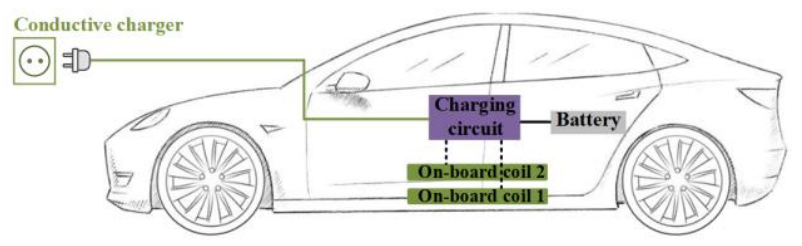

(b)

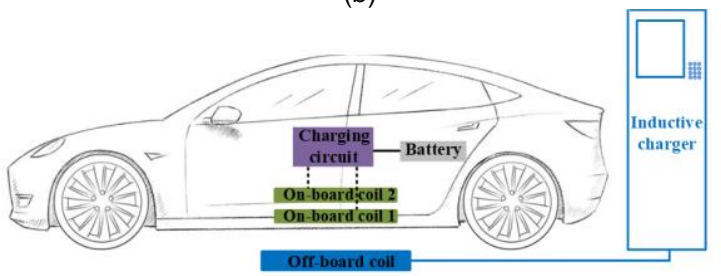

(c)

Fig. 1. (a) Proposed concept of inductive and conductive EV hybrid charger: (b) conductive mode, (c) inductive mode.

\section{AnAlysis of the Proposed HyBrid ChaRger}

\section{A. The circuit configuration}

Fig. 2a presents the proposed EV hybrid charger system showing the DC/DC stage only. which is compatible with both conductive and inductive charging methods. In the context of this paper, the conductive charging term refers to the complete on-board vehicle charger system, which is directly connected to the AC mains by means of the charging cables. When charging conductively all on-board vehicle components shown in Fig. 2a are fully utilized. When charging inductively the coil from the off-board inductive charger powers all on-board components. The on-board part includes the on-board inverter $\left(S_{11}, S_{21}, S_{31}\right.$ and $S_{41}$ ), on-board coils $L_{1}$ and $L_{2}$, resonant capacitors $C_{1}$ and $C_{2}$, rectifier $\left(D_{1}, D_{2}, D_{3}\right.$ and $\left.D_{4}\right)$ and filter capacitors $C_{i n 1}$ and $C_{o}$. The off-board vehicle part consists of the off-board inverter $\left(S_{12}, S_{22}, S_{32}\right.$ and $S_{42}$ ), off-board coil $L_{3}$, LCC resonant tank ( $L_{a}, C_{a}$, and $C_{b}$ ) and the filter capacitor $C_{i n 2}$. Although the proposed system includes a passive secondary rectifier, it is compatible with solutions which include active rectifiers [19]. $V_{i n}$ is the DC input voltage in both modes while $V_{o}$ and $I_{o}$ are the charging voltage and current of the vehicle's battery. To facilitate the model and control, $V_{o}$ and $I_{o}$ are subscribed by " " 
and " $i$ " to represent conductive and inductive modes, respectively. Values of $C_{1}$ and $C_{2}$ can be adjusted depending on the charging mode thanks to the Double-Pole Double-Throw (DPDT) switches $S_{1}$ and $S_{2}$.

For simplicity, a resistive load is used to represent the output battery in both scenarios. There is no on-board DC-DC converter on the battery's side as all the control actions are implemented on the primary side. The system uses the contactor $S_{3}$ to select the charging mode: $S_{3}$ is OFF during the conductive mode and $\mathrm{ON}$ during the inductive mode. In the conductive charging mode (presented in Fig. 2b) the output power is targeted for Level 1 or 2 charging so that the conductive charger is installed on-board the vehicle. It is also noted that the conductive charger system is developed based on the FRS converters $[6,9,10]$. To guarantee high efficiency with highpower transfer capability, the air-gap between the on-board

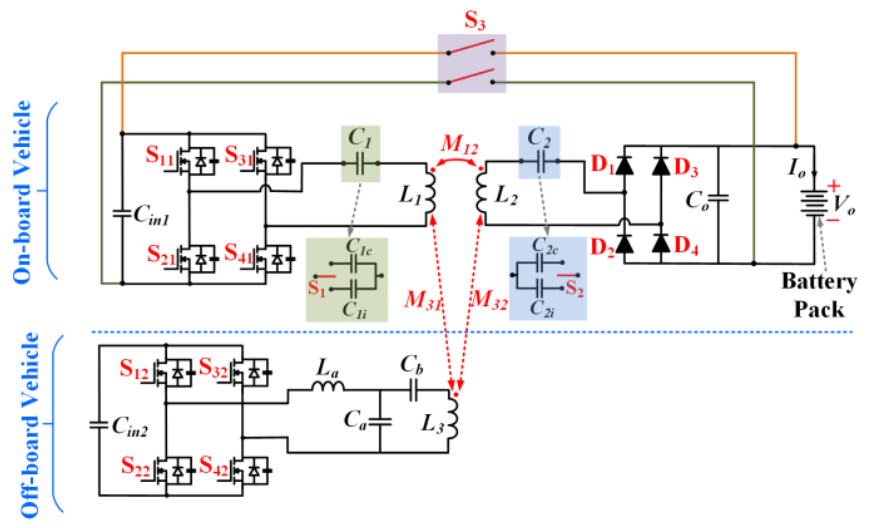

(a)

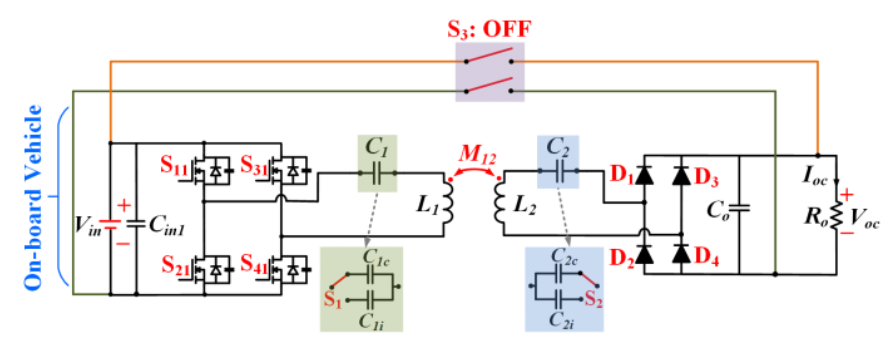

(b)

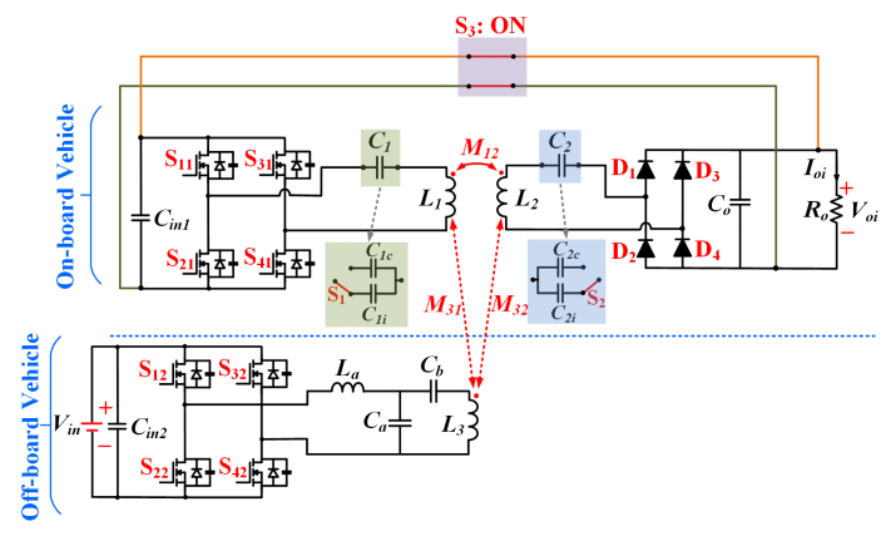

(c)

Fig. 2. (a) The proposed hybrid charger configuration with both inductive and conductive modes. (b) Conductive mode configuration. (c) Inductive mode configuration coils $L_{1}$ and $L_{2}$ is small. This results in a strong coupling between $L_{1}$ and $L_{2}$, which is modelled by the mutual inductance $M_{12}$. The values of $C_{1}$ and $C_{2}$ in the conductive mode are $C_{1 c}$ and $C_{2 c}$, respectively.

Fig. 2c presents the inductive charging mode, where the offboard part acts as the primary side with the off-board transmitter coil $L_{3}$. The proposed system utilizes both $L_{1}$ and $L_{2}$ as two receivers simultaneously harvest power from $L_{3}$. To enable the utilization of $L_{1}, C_{1}$ and the on-board inverter, $S_{3}$ is switched $\mathrm{ON}$ so that another path for the power transfer is created. As a result, there will be two power transfer paths thanks to mutual inductances $M_{31}$ and $M_{32}$. In these paths, the values of $C_{1}$ and $C_{2}$ in the inductive mode are $C_{1 i}$ and $C_{2 i}$, respectively. While the first path goes through $L_{1}, C_{1 i}$ and the on-board full-bridge inverter (performing as a rectifier), the second one utilizes $L_{2}$, $C_{2 i}$ and the on-board full-bridge rectifier. The outputs of the two paths are connected in parallel to charge the on-board battery. By utilizing two different power transfer paths, the inductive charging mode can deliver higher power to the battery with the same VA ratings of the on-board components. However, it is necessary to take into account that $L_{1}$ and $L_{2}$ are physically placed closed to each other and cross coupling $M_{12}$ is relevant in the inductive mode [27]. This could cause higher current stresses through the resonant components in the on-board side as well as a reduction of the output power. In order to alleviate this effect, $C_{1 i}$ and $C_{2 i}$ are suitably designed to effectively cancel the induced voltages caused by $M_{12}$, as shown in Section II. D.

\section{B. The proposed coupler coils system}

This section presents the proposed magnetic coupler to realize the hybrid charger, as shown in Fig. 3. The dimension of each coil and the air-gap between different coils are selected to be suitable for the EVs application. Both on-board coils $L_{1}$ and $L_{2}$ have an identical dimensions of $600 \mathrm{~mm} \times 600 \mathrm{~mm}$ and they are placed in parallel planes where coil $L_{2}$ is placed on top of $L_{1}$. The off-board coil $L_{3}$ is implemented with a larger dimension of $800 \mathrm{~mm} \mathrm{x} 800 \mathrm{~mm}$ for a better tolerance with coil misalignment (a common requirement in inductive chargers). The air-gap between $L_{1}$ and $L_{2}$ (i.e. $d_{1}$ ) is selected as $20 \mathrm{~mm}$ while the air-gap $d_{2}$ between $L_{3}$ and $L_{1}$ is set at $150 \mathrm{~mm}$. To improve the coupling coefficients in the inductive charging mode between $L_{3}$ and $L_{1}$ as well as between $L_{3}$ and $L_{2}$, the ferrite cores are installed at the bottom and the top of the coupler system. The coupling coefficients are defined as $k_{12}$ (between $L_{1}$ and $L_{2}$ ), $k_{31}$ (between $L_{1}$ and $L_{3}$ ) and $k_{32}$ (between $L_{3}$ and $L_{2}$ ). The parameters describing the magnetic coupler are listed in Table I.

The Finite-Element Analysis (FEA) of the magnetic coupler is conducted in ANSYS Maxwell 3D software and the obtained results are presented in Fig. 4. The coupling coefficient $k_{12}$ constantly appears as 0.83 because the position between $L_{1}$ and $L_{2}$ does not change. Fig. 4 illustrates the values of the coupling coefficients $k_{31}$ and $k_{32}$ against the varying misalignments. Under conditions of $15-\mathrm{cm}$ air-gap and a severe $30-\mathrm{cm}$ 
misalignment, $k_{31}$ and $k_{32}$ still achieve $56 \%$ and $55.4 \%$ of the maximum coupling coefficients.

The electromagnetic irradiation (EMI) surrounding the magnetic coupler is shown in Fig. 5 in both conductive and inductive mode with the output power of $3 \mathrm{~kW}$. It is noted that the shielding material is not included in the simulation model. It is demonstrated that the coupler complies with the ICNIRP exposure limits [28] as the simulated flux density is below 27 $\mu \mathrm{T}$ at the positions of $25 \mathrm{~cm}$ and $30 \mathrm{~cm}$ away from the edge of the coupler in the conductive and inductive mode, respectively. In the real scenarios, the vehicle chassis can be considered as a shielding plate to cover the entire on-board coils. This helps to reduce the field level on the area above the coil $L_{2}$ (e.g. inside the vehicle) to be within acceptable limits [29].
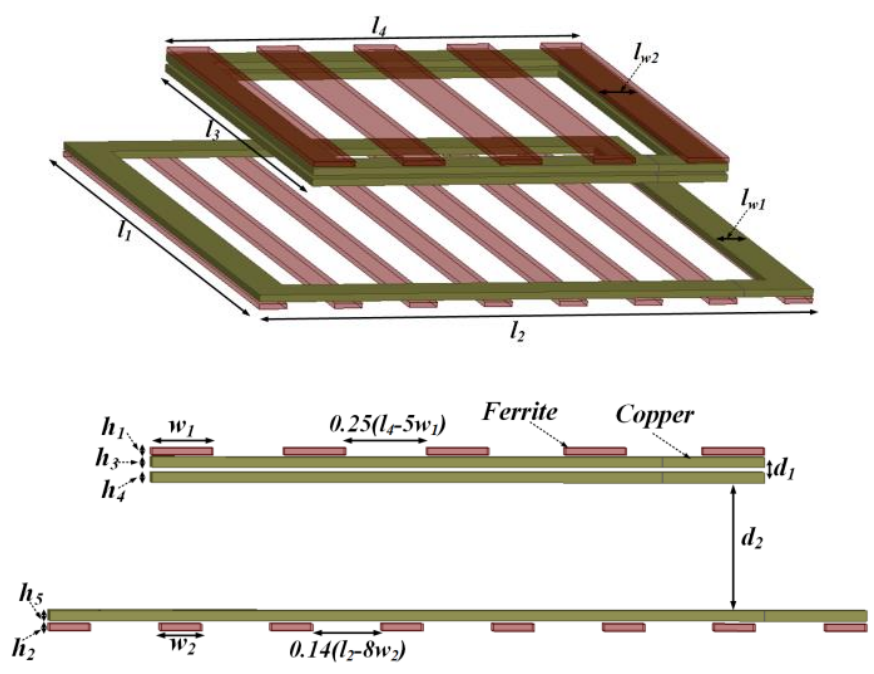

Fig. 3. Structure and dimensions of the magnetic coupler for the proposed hybrid charger system.

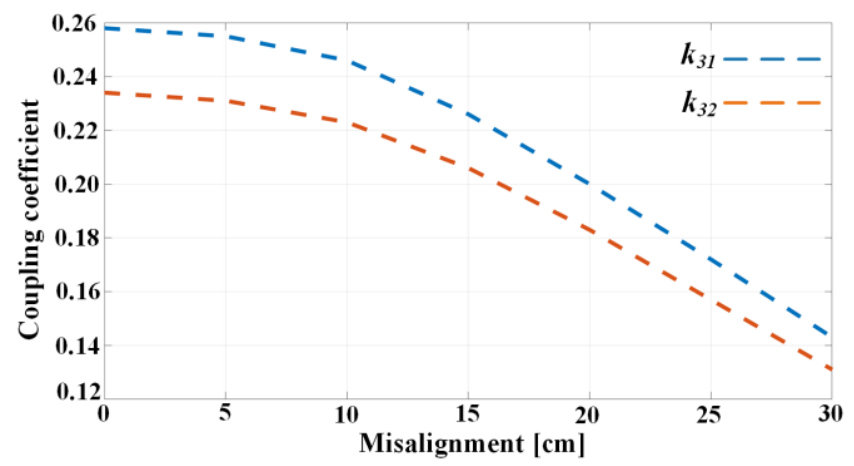

Fig. 4. FEA simulation results of the variations of $M_{31}$ and $M_{32}$ against misalignment.

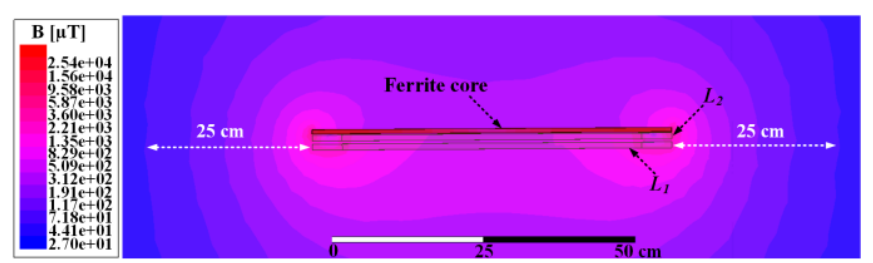

(a)

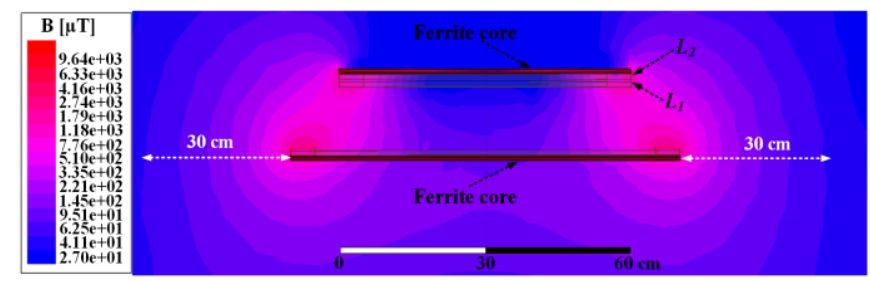

(b)

Fig. 5. FEA simulation results of the EMI level surrounding the magnetic coupler in (a) conductive mode and (b) inductive mode.

TABLE I

PARAMETERS DESCRIBING THE HYBRID CHARger Coupler

\begin{tabular}{ccc}
\hline \hline Parameter & Definition & Value \\
\hline$l_{1}, l_{2}$ & $\begin{array}{c}\text { Length and width of the off-board coil } L_{3} \\
\text { Length and width of the on-board coils } L_{l} \\
\text { and } L_{2}\end{array}$ & $800 \mathrm{~mm}$ \\
$l_{3}, l_{4}$ & Width of the copper wire of $L_{3}$ & $600 \mathrm{~mm}$ \\
$l_{w 1}$ & Width of the copper wire of $L_{l}$ and $L_{2}$ & $80 \mathrm{~mm}$ \\
$l_{w 2}$ & Width of ferrite cores on the top & $60 \mathrm{~mm}$ \\
$w_{1}$ & Width of ferrite cores on the bottom & $60 \mathrm{~mm}$ \\
$w_{2}$ & Thickness of the ferrite cores (both top and & $40 \mathrm{~mm}$ \\
$h_{1}, h_{2}$ & thottom) & $4 \mathrm{~mm}$ \\
$h_{3}, h_{4}, h_{5}$ & Thickness of the copper windings & $5 \mathrm{~mm}$ \\
$d_{1}$ & Airgap between $L_{l}$ and $L_{2}$ & $20 \mathrm{~mm}$ \\
$d_{2}$ & Airgap between $L_{3}$ and $L_{l}$ & $150 \mathrm{~mm}$
\end{tabular}

\section{Modelling and Analysis in the Conductive Mode}

Fig. 6 shows the AC equivalent circuit in the conductive charging mode using the transformer model and fundamental approximation. The variables $v_{i n c_{-} a c}, v_{o c_{-} a c}$ and $i_{o c_{-} a c}$ in (1) are the first harmonic components of the input voltage, output voltage and current of the resonant circuit, respectively. In the following analysis, $\mathrm{V}_{\mathrm{inc}}, \mathrm{V}_{\mathrm{oc}}$ and $\mathrm{I}_{\mathrm{oc}}$ are used to express the phasor form of $v_{\text {inc_ac }}(t), v_{o c_{-} a c}(t)$ and $i_{o c_{-} a c}(t) . R_{a c}$ in (1) is the equivalent battery impedance and $f_{c}$ is the inverter's switching frequency at conductive mode. To simplify the analysis, the turn ratio between $L_{1}$ and $L_{2}$ is selected as 1 and $L_{1}=L_{2} . \theta_{c}$ is the phase-shift between $V_{\text {inc }}$ and $V_{o c}$. The voltage gain transfer function $\mathrm{G}_{\mathrm{v}}$ (2) and the input impedance $Z_{\text {in }}$ (3) are obtained by (2) and (3) respectively based on the AC equivalent circuit [6]. The voltage gain curves and phase of $Z_{\text {in }}$ for the converter under different load conditions are shown in Fig. 7.

$$
\begin{gathered}
v_{\text {inc_ac }}(t)=\frac{4}{\pi} V_{i n} \sin \left(2 \pi f_{c} t\right) \\
v_{o c_{-} a c}(t)=\frac{4}{\pi} V_{o c} \sin \left(2 \pi f_{c} t+\theta_{c}\right) \\
i_{o c_{-} a c}(t)=\frac{\pi}{2} I_{o c} \sin \left(2 \pi f_{c} t+\theta_{c}\right) \\
R_{a c}=\frac{8}{\pi^{2}} \frac{V_{o c}}{I_{o c}}=\frac{8}{\pi^{2}} R_{o} ; \omega_{c}=2 \pi f_{c} \\
G_{v}=\frac{\mathrm{V}_{\mathrm{oc}}}{\mathrm{V}_{\mathrm{inc}}}=
\end{gathered}
$$$$
G_{v}=\frac{\mathrm{V}_{\mathrm{oc}}}{\mathrm{V}_{\mathrm{inc}}}=
$$$$
Z_{\text {in }}=Z_{1}+\frac{Z_{2} Z_{3}}{Z_{2}+Z_{3}}
$$ 
where $Z_{1}=j \omega_{c}\left(L_{1}-M_{12}\right)+1 / j \omega_{c} C_{1 c}, Z_{2}=j \omega_{c} M_{12}$ and $Z_{3}=$ $j \omega_{c}\left(L_{2}-M_{12}\right)+1 / j \omega_{c} C_{2 c}+R_{a c}$.

The voltage gain $G_{v}$ is unity at the series resonant frequency $f_{o}$, which is expressed as:

$$
f_{o}=\frac{1}{2 \pi \sqrt{\left(L_{1}-M_{12}\right) C_{1 c}}}=\frac{1}{2 \pi \sqrt{\left(L_{2}-M_{12}\right) C_{2 c}}}
$$

According to Fig. 7, voltage gain curves can be divided into two different regions depending on $f_{c}$, namely regions 1 and 2 :

(1) Region $1\left(f_{c}<f_{o}\right)$, where the gain curves have either negative or positive slope with high sensitivity (i.e. high slope value). A small variation of $f_{c}$ cause a large output voltage variation. The gain is always greater than unity regardless of the load conditions while the phase of $Z_{\text {in }}$ is either negative or positive depending on $f_{c}$.

(2) Region $2\left(f_{c} \geq f_{o}\right)$ : in this region, the gain curves have negative slope with low sensitivity (e.g. low slope value). The gain of the circuit is always less than unity under any output load condition. Therefore, linear control is possible over the entire operating frequency range [6]. The phase of $Z_{\text {in }}$ is always positive in this region, which enables Zero Voltage Switching (ZVS) operation for the inverter's switches. Note, that the efficiency of the CM converter deteriorates during nonresonance conditions as the operating frequency is regulated to implement the constant current-constant voltage charging profile in Fig. 7.

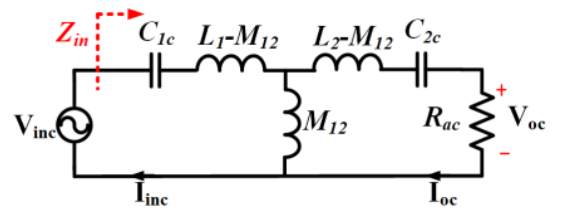

Fig. 6. AC equivalent circuit in the conductive charging mode.

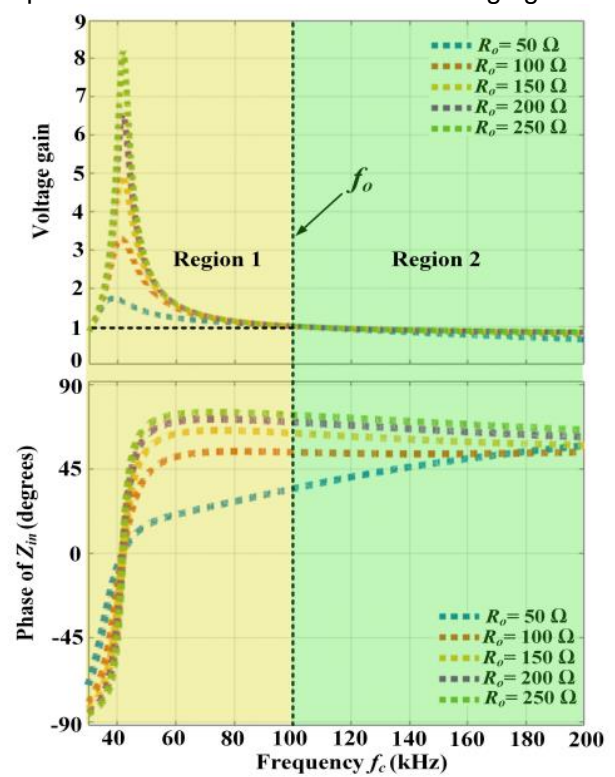

Fig. 7. Voltage gain and phase of input impedance of the proposed hybrid system in the conductive mode versus operating frequencies with $L_{1}=L_{2}=115 \mu \mathrm{H}, M_{12}=95.4 \mu \mathrm{H}, C_{1}=C_{2}=127 \mathrm{nF}$.

\section{Modelling and Analysis in the Inductive Mode}
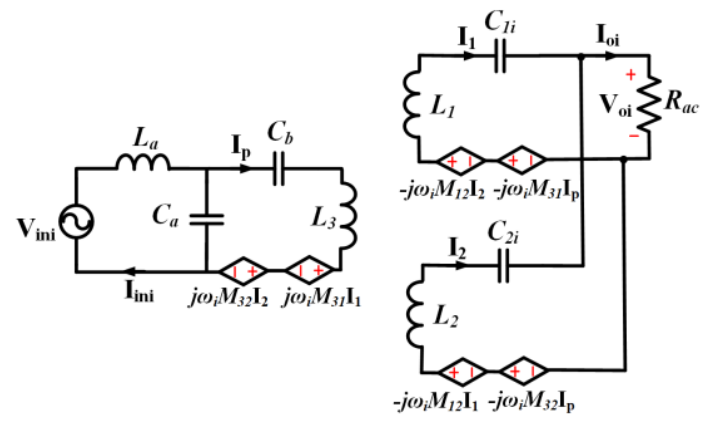

Fig. 8. AC equivalent circuit in the inductive mode.

This section focuses on modeling and analyzing the operation with at inductive mode. The circuit configuration in Fig. 2(c) is modeled by the AC equivalent circuit in Fig 8 . The $M$ model is adopted in Fig. 8 since this enables independent analysis at both sides of the circuit [13]. Similar to Section II. C, $\mathrm{V}_{\text {ini }}, \mathrm{V}_{\mathrm{oi}}$ and $\mathrm{I}_{\mathrm{oi}}$ are used to express the complex form of the corresponding fundamental variables $v_{\text {ini_ac }}, v_{o i_{-} a c}$ and $i_{o i_{-} a c}$. While $v_{o i_{-} a c}$ and $i_{o i_{-} a c}$ are defined exactly the same as $v_{o c_{-} a c}$ and $i_{o c_{-} a c}$ in (1) respectively (i.e. $5 \mathrm{~b}$ and $5 \mathrm{c}$ ), $v_{\text {ini_ac }}$ is given as shown in (5a). According to that, the DC input voltage $V_{\text {in }}$ can be modulated by $\mathrm{S}_{12}, \mathrm{~S}_{22}, \mathrm{~S}_{32}, \mathrm{~S}_{42}$ with $D$ being the effective duty cycle of the inverter's output voltage. To effectively control $D$, the phase shift angle $\alpha$ between the two inverter's legs is utilized. Eq. (6) expresses the relationship between $\alpha$ and $D$ [30].

$$
\begin{aligned}
v_{\text {ini_ac }}(t) & =\frac{4}{\pi} V_{i n} \sin \frac{\pi D}{2} \sin (2 \pi f t) \\
v_{o i_{-} a c}(t) & =\frac{4}{\pi} V_{o i} \sin \left(2 \pi f t+\theta_{i}\right) \\
i_{o i_{-} a c}(t) & =\frac{\pi}{2} I_{o i} \sin \left(2 \pi f t+\theta_{i}\right) \\
\alpha & =(1-D) \pi
\end{aligned}
$$

Differentiating from the conductive mode, the switching frequency $\left(f_{i}\right)$ in the inductive mode is fixed to be $85 \mathrm{kHz}$, in accordance with SAE J2954 standard [17]. Therefore, the phase shift angle $\alpha$ is utilized to control the battery voltage and current in the inductive mode. The voltage equation of the primary side can be obtained as (7) by applying Kirchhoff's Law to the model in Fig. 8.

$$
V_{i n i}=\left(j \omega L_{a}-j \frac{1}{\omega C_{a}}\right) \mathrm{I}_{\mathrm{ini}}-\frac{1}{j \omega C_{a}} \mathrm{I}_{p}
$$

The transmitter's current $I_{p}$ can be controlled through the input voltage $V_{\text {ini }}$ as (8) if $L_{a}$ and $C_{a}$ are selected to resonate at the switching frequency $f_{i}\left(\omega_{i}=2 \pi f_{i}\right)$. Section III explains how the value of $I_{p}$ is calculated based on the output voltage. The value of $C_{b}$ is then determined by (10) according to [13-14].

$$
\begin{gathered}
\mathrm{I}_{p}=-j \omega_{i} C_{a} \mathrm{~V}_{\mathrm{ini}} \\
\omega_{i} L_{a}-\frac{1}{\omega_{i} C_{a}}=0 \\
C_{b}=\frac{1}{\omega_{i}^{2}\left(L_{1}-L_{a}\right)}
\end{gathered}
$$

Similarly, the voltage equations of secondary resonant tanks can be obtained from (11) and (12), in which $j \omega_{i} M_{12} I_{2}$ and $j \omega_{i} M_{12} I_{1}$ are the induced voltages caused by the cross mutual inductance $M_{12}$ from the other receiver. $M_{12}$ induces voltages on both receivers and therefore reduces the output voltage and 
power, as well as causes higher current stresses on the primary inverter [28].

$$
\begin{aligned}
& j \omega_{i} M_{12} \mathrm{I}_{2}+j \omega_{i} L_{1} \mathrm{I}_{1}+\frac{1}{j \omega_{i} C_{1 i}} \mathrm{I}_{1}+\mathrm{V}_{\mathrm{oi}}=j \omega_{i} M_{31} \mathrm{I}_{\mathrm{p}} \\
& j \omega_{i} M_{12} \mathrm{I}_{1}+j \omega_{i} L_{2} \mathrm{I}_{2}+\frac{1}{j \omega_{i} C_{2 i}} \mathrm{I}_{2}+\mathrm{V}_{\mathrm{oi}}=j \omega_{i} M_{32} \mathrm{I}_{\mathrm{p}}
\end{aligned}
$$

To eliminate the above crossing voltages, the series capacitors $C_{1 i}$ and $C_{2 i}$ are used. To simplify the design of these capacitors, the receiver's currents are assumed to be identical (i.e. $\mathrm{I}_{1} \approx \mathrm{I}_{2}$ ). Finally, $C_{1 i}$ and $C_{2 i}$ can be calculated as (13) and (14), respectively.

$$
\begin{aligned}
C_{1 i} & =\frac{1}{\omega_{i}^{2}\left(L_{1}+M_{12}\right)} \\
C_{2 i} & =\frac{1}{\omega_{i}^{2}\left(L_{2}+M_{12}\right)}
\end{aligned}
$$

It can be noticed from (13) and (14) that the series capacitors $C_{1 i}\left(C_{2 i}\right)$ are used here for two purposes: (1) to be resonant with $L_{1}\left(L_{2}\right)$ and (2) to suppress the crossing induced voltages caused by $M_{21}$.

Therefore, the output voltage $V_{o i}$ at the angular resonant frequency $\omega_{i}$ is expressed by (15) when considering the conditions described by (13) and (14). It is noted that $V_{o i}$ is irrelevant to the load's impedance and is in phase with $V_{\text {ini }}$. From (5) and (15), the DC output voltage $V_{o i}$ can be written as (16). To demonstrate the relationship between $V_{o i}$ and $\alpha$, Fig. 9 is presented by combining (6) and (16).

$$
\begin{gathered}
\mathrm{V}_{\mathrm{oi}}=j \omega_{i} M_{31} \mathrm{I}_{\mathrm{p}}=\omega_{i}^{2} M_{31} C_{a} \mathrm{~V}_{\mathrm{ini}} \\
V_{o i}=\omega_{i}^{2} M_{31} C_{a} V_{i n} \sin \frac{\pi D}{2}
\end{gathered}
$$

The total output current $I_{o i}$ is summed up from the output currents of both secondary side circuits (i. e. $I_{o i}=I_{1}+I_{2}$ ), which varies depending on different load conditions. Therefore, the proposed charger enables providing higher current charging capability in the inductive mode with the same VA rating of the on-board components. The output power in the inductive mode is written as follows:

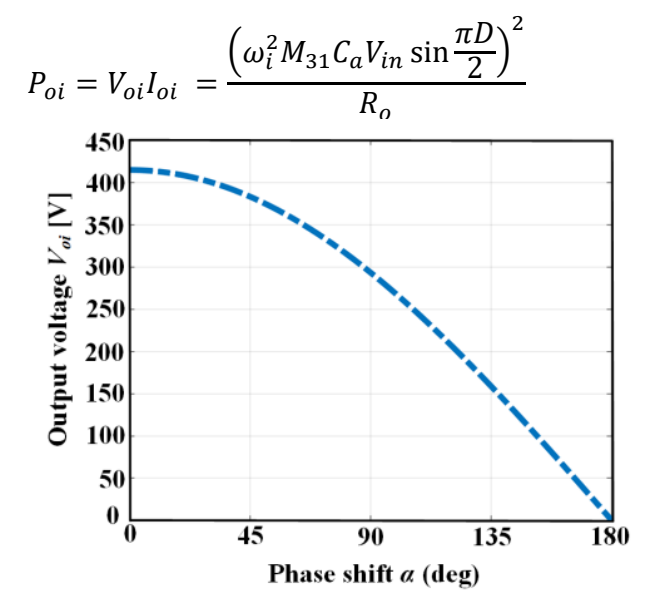

Fig. 9. DC output voltage $V_{o i}$ versus the phase shift $\alpha$ in the inductive mode.

In the inductive mode, the mutual inductance difference between $M_{31}$ and $M_{32}$ (i.e. $\Delta M=\left|M_{31}-M_{32}\right|$ ) is inevitable. The reason is that the receiver coil $L_{1}$ is positioned slightly closer to the transmitter coil $L_{3}$ than the receiver coil $L_{2}$. This causes a circulating current in the secondary circuits and consequently higher conduction losses are generated [31-32]. To effectively demonstrate this issue, several simulation results are shown in Fig. 10 with different values of $\Delta M$. It can be easily noticed that the higher $\Delta M$, the higher the circulating current will be. This current is defined as $I_{12}$ in (18).

$$
I_{12}=I_{1}-I_{2}
$$

It is essential to minimize the circulating current by reducing $\Delta M$ in the magnetic coupler design. In this work, the values of $M_{31}$ and $M_{32}$ are designed as $30.29 \mu \mathrm{H}$ and $27.52 \mu \mathrm{H}$, respectively, with $d_{1}=20 \mathrm{~mm}$ and $d_{2}=150 \mathrm{~mm}$. This results in a small circulating current of $0.9 \mathrm{~A}$, which can be neglected to simplify the analysis.

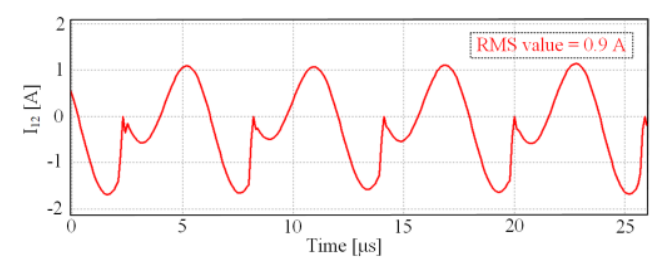

(a)

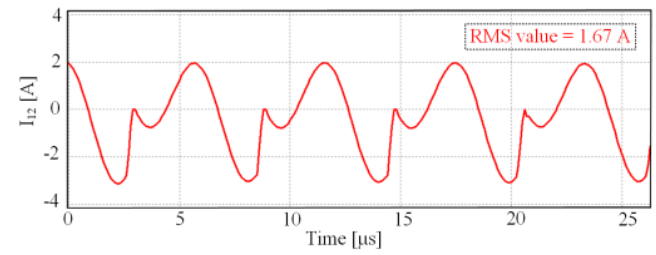

(b)

Fig. 10. Circulating current simulation results with different $\Delta M$ at the rated load. (a) $M_{31}=30.29 \mu \mathrm{H}, M_{32}=27.52 \mu \mathrm{H}$ with $d_{2}=150 \mathrm{~mm}, d_{1}=$ $20 \mathrm{~mm}$. (b) $M_{31}=33.31 \mu \mathrm{H}, M_{32}=27.52 \mu \mathrm{H}$ with $d_{2}=130 \mathrm{~mm}, d_{1}=$ $40 \mathrm{~mm}$.

\section{DESIGN CONSIDERATIONS}

This section comprehensively presents the design considerations of the proposed hybrid converter. There are several points that need to be clarified:

1) The design of the coupler coils including $L_{1}, L_{2}$ and $L_{3}$ must be selected to fit within the available space in the vehicle chassis. The coupler is designed to achieve high coupling coefficients, good tolerance with misalignment and low EMI in both charging modes.

2) The operating frequency in the conductive mode $f_{c}$ is different from that of the inductive mode $f_{i} . f_{c}$ should be high enough to reduce the size of the resonant components and the output filter capacitor as well as the voltage stress across the resonant capacitors. However, $f_{c}$ should not be much higher compared to $f_{i}$ to facilitate the component's design. In this work, while $f_{i}$ is fixed at $85 \mathrm{kHz}, f_{c}$ is variable from $100 \mathrm{kHz}$ to $135 \mathrm{kHz}$.

3) The proposed converter should be designed to achieve softswitching condition of ZVS for MOSFET switches to minimize switching losses and improve efficiency in both modes.

4) Both charging modes work with a CC-CV profile as depicted in Fig. 11. 


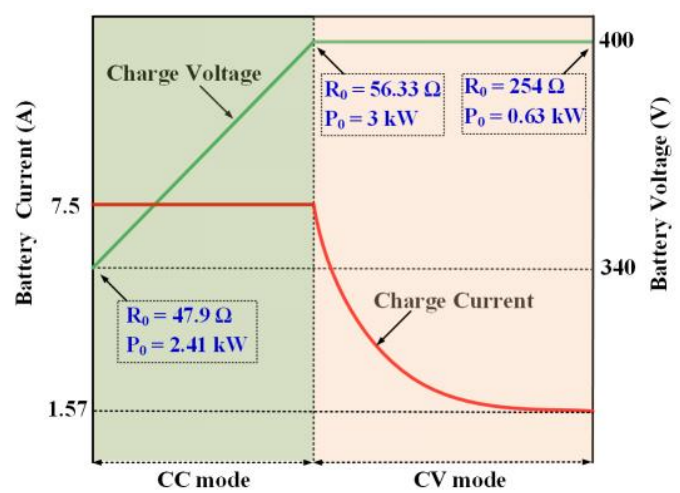

Fig. 11. The Constant Current/Constant Voltage (CC/CV) battery charging profile and their equivalent impedance.

The flowchart in Fig. 12 presents the practical design procedure for the proposed hybrid charger in both modes. The first step is to calculate the range of the equivalent resistance $R_{o}$ and the voltage gain $G_{v}$ from the CC/CV charging profile in Fig. 11. $V_{o}$ varies from $340 \mathrm{~V}$ to $400 \mathrm{~V}$ [33] while $I_{o}$ varies from 1.57 A to $7.5 \mathrm{~A}$ with the maximum power of $3 \mathrm{~kW}$. The battery equivalent impedance $R_{O}$ is defined in (19) according to [13].

$$
R_{o}=\frac{V_{o}}{I_{o}}
$$

Therefore, $R_{o}$ accordingly varies from $45.3 \Omega$ to $254 \Omega$ for the entire charging process. In the experiment, an electronic load is used to represent the battery with different battery states. The voltage gain requirement of the converter is $0.85 \sim 1$ in both charging modes, with a normal voltage gain of 1 when $V_{o}=400$ $\mathrm{V}$. Therefore, the coil turns ratio between $n_{1}$ and $n_{2}$ is to be nearly 1 .

In the conductive mode, the resonant frequency $f_{o}$ is selected as $100 \mathrm{kHz}$. In order to achieve ZVS operation for primary MOSFET switches, the value of $M_{12}$ is calculated as (20) based on [6,8] with $f_{o}$ of $100 \mathrm{kHz}$, a dead-time $t_{d e}$ of $200 \mathrm{~ns}$ and a output capacitance $C_{\text {oss }}$ of $220 \mathrm{pF}$.

$$
M_{12} \leq \frac{t_{d e}}{16 f_{o} C_{\text {oss }}}=568 \mu \mathrm{H}
$$

A maximum value of $568 \mu \mathrm{H}$ or less will ensure ZVS for the primary-side switches. However, $M_{12}$ cannot be too small as it will decrease the power transfer capability and increase the conduction losses of the primary side. Moreover, it is observed from the simulation results of the voltage gain that the gain in the CM is limited, and there is bifurcation issue if $M_{12}>$ $250 \mu \mathrm{H}$. Considering that the available dimensions of $L_{1}$ and $L_{2}$ are $600 \mathrm{~mm} \times 600 \mathrm{~mm}$, the value of $M_{12}$ is designed as $95 \mu \mathrm{H}$ with an associated air-gap of $20 \mathrm{~mm}$ between two on-board coils $\left(d_{1}\right)$ in this work.

Next, the number of turns and ferrite's volume is initialized using FEA software to estimate values for $L_{1}$ and $L_{2}$ with the dimensions of $600 \mathrm{~mm} \times 600 \mathrm{~mm}$. It is worth noting that the ferrite core on the top is placed closer to $L_{2}$ winding than to $L_{1}$ winding. Therefore the number of turns of $L_{2}$ (i.e. $n_{2}$ ) needs to be slightly lower than of $L_{1}$ (i.e. $n_{1}$ ) so that $L_{1}$ and $L_{2}$ have the same inductance. After several trial and errors in both simulations and experiments, final parameters of $n_{1}$ and $n_{2}$ are selected as 8.5 and 8 while both $L_{1}$ and $L_{2}$ inductances are equal to $115 \mu \mathrm{H}$ to meet with the system requirements. Finally, $C_{1 c}$ and $C_{2 c}$ can be calculated as (21) by using (4).
TABLE ॥

\begin{tabular}{|c|c|c|}
\hline Parameter & Definition & Value \\
\hline$V_{\text {in }}$ & Input DC voltage & $400 \mathrm{~V}$ \\
\hline$V_{o}$ & Output DC voltage & $340-400 \mathrm{~V}$ \\
\hline$I_{o}$ & Output DC current & $1.57-7.5 \mathrm{~A}$ \\
\hline$P_{o}$ & Rated output power & $3 \mathrm{~kW}$ \\
\hline$R_{o}$ & Equivalent output resistance & $45.3-255 \Omega$ \\
\hline$f_{o}$ & Resonant frequency in the $\mathrm{CM}$ & $100 \mathrm{kHz}$ \\
\hline$f_{c}$ & Operating frequency in the $\mathrm{CM}$ & $100-140 \mathrm{kHz}$ \\
\hline$f_{i}$ & Operating frequency in the IM & $85 \mathrm{kHz}$ \\
\hline$L_{1}, L_{2}$ & Self-inductance of on-board coils & $115 \mu \mathrm{H}$ \\
\hline$n_{1}$ & Number of turns of $L_{l}$ & 8.5 \\
\hline$n_{2}$ & Number of turns of $L_{2}$ & 8 \\
\hline$M_{12}$ & Magnetizing inductance between $L_{l}$ and $L_{2}$ & $95.4 \mu \mathrm{H}$ \\
\hline$C_{1 c}, C_{2 c}$ & Resonant capacitors in the $\mathrm{CM}$ & $127 \mathrm{nF}$ \\
\hline$L_{3}$ & Self-inductance of off-board coil & $120 \mu \mathrm{H}$ \\
\hline$n_{3}$ & Number of turns of $L_{3}$ & 7 \\
\hline$M_{31}$ & Magnetizing inductance between $L_{3}$ and $L_{1}$ & $16.8-29.6 \mu \mathrm{H}$ \\
\hline$M_{32}$ & Magnetizing inductance between $L_{3}$ and $L_{2}$ & $16.2-28.1 \mu \mathrm{H}$ \\
\hline$L_{a}$ & Resonant inductor in the IM & $29.2 \mu \mathrm{H}$ \\
\hline$C_{a}$ & Primary parallel capacitor in the IM & $120 \mathrm{nF}$ \\
\hline$C_{b}$ & Primary series capacitor in the IM & $35 \mathrm{nF}$ \\
\hline$C_{I i}, C_{2 i}$ & Secondary capacitors in the CM & $17.4 \mathrm{nF}$ \\
\hline$R_{l}, R_{2}, R_{3}$ & Parasitic resistance of coil $L_{1}, L_{2}, L_{3}$ & $\begin{array}{c}0.15 \Omega, 0.157 \\
\Omega, 0.2 \Omega\end{array}$ \\
\hline$R_{C l c}, R_{C 2 c}$ & Parasitic resistance of capacitors $C_{l c}, C_{2 c}$ & $0.0224 \Omega$ \\
\hline$R_{C l i}, R_{C 2 i}$ & Parasitic resistance of capacitors $C_{1 i}, C_{2 i}$ & $0.035 \Omega$ \\
\hline$R_{C a}$ & Parasitic resistance of capacitor $C_{a}$ & $0.027 \Omega$ \\
\hline$R_{C b}$ & Parasitic resistance of capacitor $C_{b}$ & $0.07 \Omega$ \\
\hline & $\frac{1}{\left.2 \pi f_{o}\right)^{2}\left(L_{1}-M_{12}\right)}=127 \mathrm{nF}(i=1,2)$ & $(21)$ \\
\hline
\end{tabular}

SPECIFICATION AND PARAMETERS OF THE HYBRID CHARGER SYSTEM

In the inductive mode, the design of the off-board coil $L_{3}$ needs to be performed to achieve high coupling coefficients ( $k_{31}$ and $k_{32}$ ) and good tolerance with misalignment according to the system's specification. A way to achieve the above goal is to utilize $L_{3}$ with a dimension larger than the one of the two onboard coils. In details, $L_{3}$ is implemented with a size of $800 \mathrm{~mm}$ x $800 \mathrm{~mm}$. Similar to the CM, the inductance of $L_{3}$ and its number of turns $n_{3}$ are determined as $120 \mu \mathrm{H}$ and 8 turns, respectively, by using the FEA simulation.

On the other hand, the mutual inductances difference $\Delta M$ needs to be as small as possible to minimize the circulating current. The RMS value of the current $I_{p}$ through $L_{3}$ is determined as (22) based on (15) when $V_{o i}=400 \mathrm{~V}, f_{i}=85 \mathrm{kHz}$ and $M_{31}=$ $29.6 \mu \mathrm{H}$.

$$
I_{p_{\_} r m s}=\frac{\frac{4}{\pi} V_{o i}}{\sqrt{2} *\left(2 \pi f_{i}\right) * M_{31}}=23 \mathrm{~A}
$$

Then, $C_{a}$ is calculated as (23) based on (8) with $I_{p_{-} r m s}=23 \mathrm{~A}$, $V_{\text {in }}=400 \mathrm{~V}, f_{i}=85 \mathrm{kHz}$.

$$
C_{a}=\frac{\sqrt{2} I_{p_{-} r m s}}{\left(\frac{4}{\pi} V_{\text {in }}\right) *\left(2 \pi f_{i}\right)}=120 \mathrm{nF}
$$

The value of $L_{a}$ is calculated as $29 \mu \mathrm{H}$ by using (9) with $C_{a}=$ $120 \mathrm{nF}$. Next, $C_{b}$ is designed as (10) and slightly adjusted to achieve ZVS operation at all load conditions. In this work, $C_{b}$ is selected as $35 \mathrm{nF}$.

Finally, $C_{1 i}$ and $C_{2 i}$ are designed as (13) and (14), respectively. Both values come out as $17.4 \mathrm{nF}$. All specifications and parameters of the proposed hybrid charger are tabulated in Table II (CM and IM stand for conductive mode and inductive 
mode, respectively). Table II also includes the equivalent series resistance (ESR) of capacitors based on [37]. Due to the much lower parasitic resistances compared to the parasitic resistance of the coils, capacitors' ESR do not affect the operation of the converter but they increase conduction losses and therefore impact slightly on the efficiency. In the experiment, polypropylene film capacitors from Kemet were selected for all resonant capacitors due to their low ESR and high current carrying capability [37].

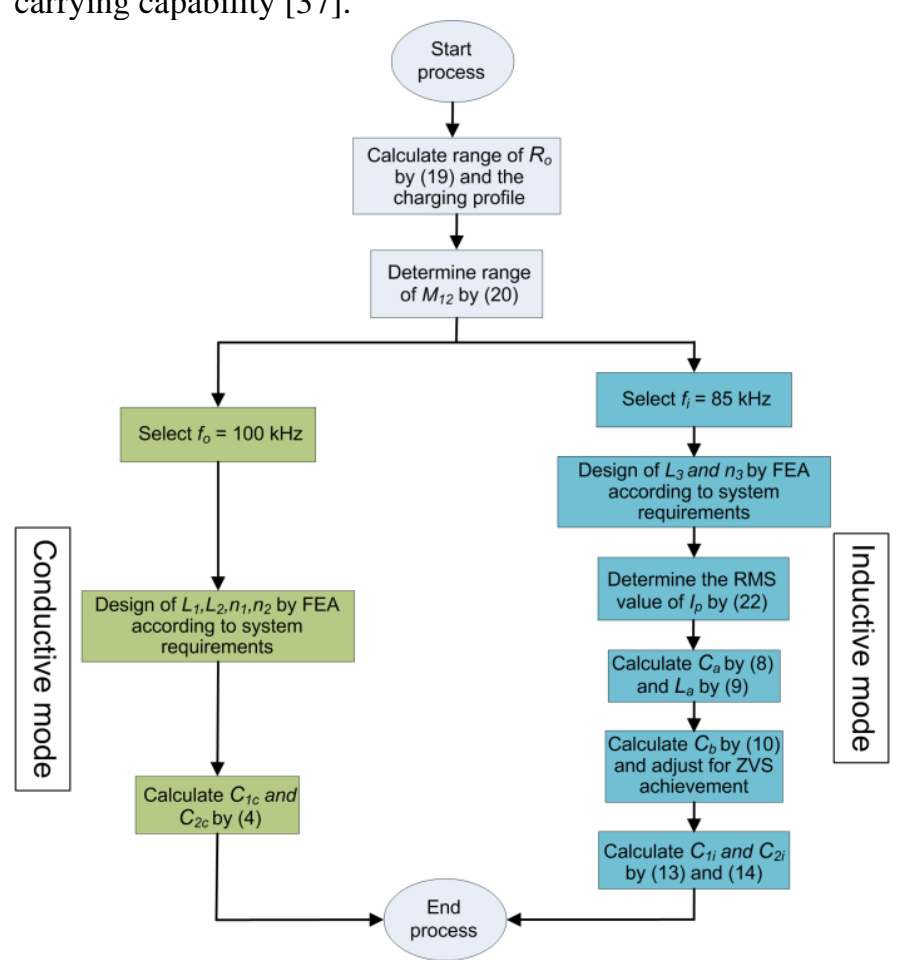

Fig. 12. Flowchart of the proposed hybrid charger design procedure.

The output voltage $V_{o}$ is controlled in both modes to attain the battery charge profile of the $\mathrm{CC} / \mathrm{CV}$ profile as illustrated in Fig. 11. The detailed control scheme in each mode of conductive and inductive is presented as follows:

a) Conductive mode: the switching frequency $f_{c}$ is adjusted to control $V_{o}$ according to the different equivalent load $R_{o}$. Since the converter works as an output voltage source at the resonant frequency $f_{o}$ of $100 \mathrm{kHz}$ (as shown in Fig. 7), the $\mathrm{CV}$ mode is implemented around $f_{o}$. During the CC mode, $R_{o}$ increases from $45.3 \Omega$ to $53.3 \Omega$ and this requires $f_{c}$ to reduce from 135 $\mathrm{kHz}$ to $105 \mathrm{kHz}$ to maintain the charging current at $7.5 \mathrm{~A}$. Moving to the $\mathrm{CV}$ mode, $f_{c}$ is only adjusted in a narrow range from $105 \mathrm{kHz}$ to $100 \mathrm{kHz}$ while $R_{o}$ increases from $53.33 \Omega$ to $254 \Omega$. The control for CM mode is implemented by the onboard controller circuit.

b) Inductive mode: as the switching frequency $f_{i}$ is required to be fixed as $85 \mathrm{kHz}$ in accordance with SAE J2954 standard, the phase shift angle $\alpha$ is used in the IM to control the off-board inverter's voltage $\mathrm{V}_{\text {ini. }}$. The converter works as an output voltage source at $f_{i}(15)$ regardless the value of $R_{o}$. Similar to CM, $\alpha$ is adjusted from 60 degrees to 5 degrees to control the charging current in $\mathrm{CC}$ mode and from 5 degrees to 0 degrees to control the charging voltage in $\mathrm{CV}$ mode. The control process in IM is implemented by the off-board controller circuit to reduce control complexity. Table III summarizes the control process in both modes of the hybrid charger system.

TABLE III

CONTROL PROCESS OF THE HYBRID SYSTEM

\begin{tabular}{|c|c|c|c|c|}
\hline Mode & $\begin{array}{c}\text { Charging } \\
\text { mode }\end{array}$ & $\begin{array}{c}\text { Frequency } \\
\text { range }[\mathrm{kHz}]\end{array}$ & $\begin{array}{c}\text { Phase-shift } \\
\text { range }\left[{ }^{\circ}\right]\end{array}$ & $\begin{array}{c}\text { Controller } \\
\text { circuit }\end{array}$ \\
\hline Conductive & $\mathrm{CC}$ & 135 to 105 & NA & On-board \\
\cline { 2 - 5 } & $\mathrm{CV}$ & 105 to 100 & NA & On-board \\
\hline \multirow{2}{*}{ Inductive } & $\mathrm{CC}$ & $\mathrm{NA}$ & 60 to 5 & Off-board \\
\cline { 2 - 5 } & $\mathrm{CV}$ & $\mathrm{NA}$ & 5 to 0 & Off-board \\
\hline
\end{tabular}

\section{EXPERIMENTAL RESULTS}

A 3-kW hybrid charger prototype is developed and tested to experimentally demonstrate its feasibility and validity as portrayed in Fig. 13(a). The parameters of the proposed coupler coils are shown in Table I while the coupler's prototype is shown in Fig. 13(b). All coil windings are constructed from the Litz wire with 600 strands and 38 AWG to reduce the conduction losses. According to the FEA electrostatic simulation, the value of the inter-winding capacitance $C_{w}$ between $L_{1}$ and $L_{2}$ is $30 \mathrm{pF}$. High value of $C_{w}$ may result in large primary current spikes and increase the noise level in the system [36]. In this work, these above issues are not observed thanks to the benefits of the resonant converters. In addition, more efforts are made to reduce $C_{w}$ in this work such as increasing the amount of insulation between winding to winding. The double Kapton-tape is lapped around the Litz copper wire to further improve the insolation in the experiment. The bottom and top ferrite are constructed using core I-N87 from TDK. As highlighted in Section II.B, the maximum airgap between $L_{3}$ and $L_{1}$ is tested at $15 \mathrm{~cm}$ in the inductive mode while the air-gap between $L_{2}$ and $L_{1}$ is fixed at $2 \mathrm{~cm}$. Please note that the relative position between $L_{3}$ and on-board coils is changed during the test while the position between $L_{2}$ and $L_{1}$ is fixed. The on-board and off-board inverters are built using SiC MOSFET C2M0025120D from Cree, so ZVS turning-on is preferable to achieve than the ZCS turning-off to minimize the switching losses [35]. Moreover, SiC-Schottky diode HFA50PA60 is selected for the on-board rectifier.

It should be noted that the series capacitor $C_{b}$ is adjusted from $42.4 \mathrm{nF}$ in simulation to $35 \mathrm{nF}$ in the experiment to achieve ZVS of all inverter switches. Other specifications and parameters of the proposed EV hybrid charger are summarized in Table II. To switch between the two charging modes, the contactor G7L-2A-X-L from Omron Electronics is implemented as $S_{3}$. During the inductive mode (IM), $S_{3}$ is on, otherwise it is off. $S_{3}$ is directly controlled from the on-board microcontroller $\mu \mathrm{C}$ and its associated circuit is shown in Fig. 14. The input/output power and efficiency of the charger is measured by a YOKOGAWA WT1600 Power Analyzer and a Chroma DC Electronic Load 63210 is used to emulate the EV battery with the charging profile shown in Fig. 11. Two switches $S_{1}$ and $S_{2}$ were implemented by the relay 4610 DPDT from Finder in the experiment. The electrical schematic is presented in Fig. 15, in which the switch $S_{1}$ utilizes contacts $T_{1}$ 
and $T_{2}$ while the switch $S_{2}$ utilizes contacts $T_{3}$ and $T_{4}$. Table IV details the control scheme for switches $S_{1}$ and $S_{2}$. The maximum power losses on the relay is $5 \mathrm{~W}$ at the rated power of $3000 \mathrm{~W}$. As such the losses are neglected in the analysis for simplicity.

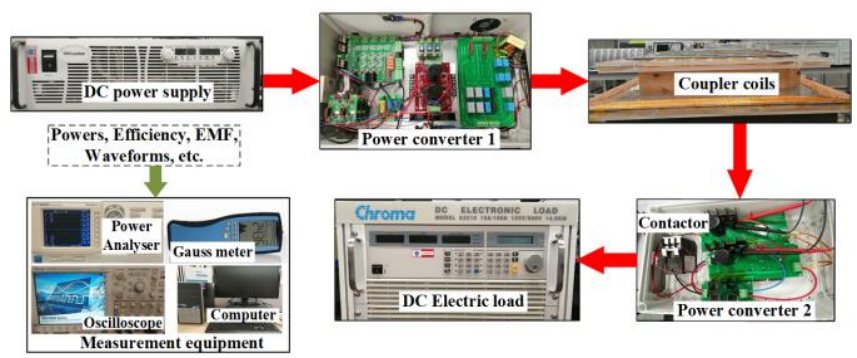

(a)
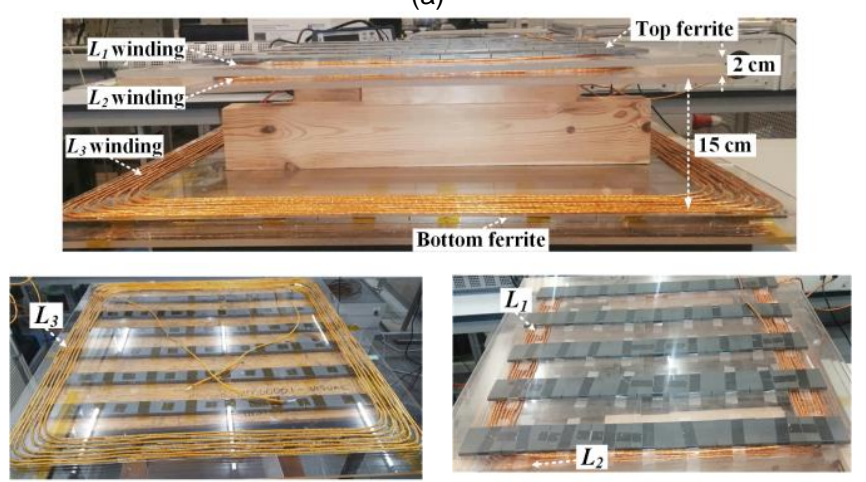

(b)

Fig. 13. (a) The experimental test-rig of the proposed hybrid EV charger, (b) Prototype of the coupler coils.

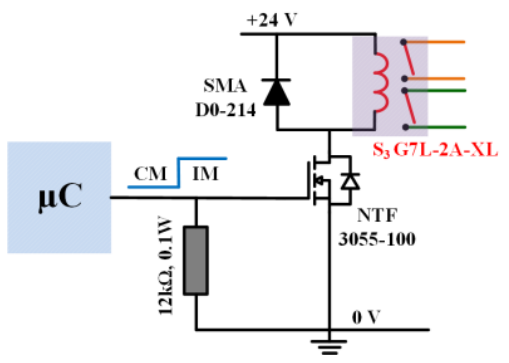

Fig. 14. The implementation for contactor $S_{3}$ and its associated control circuit.

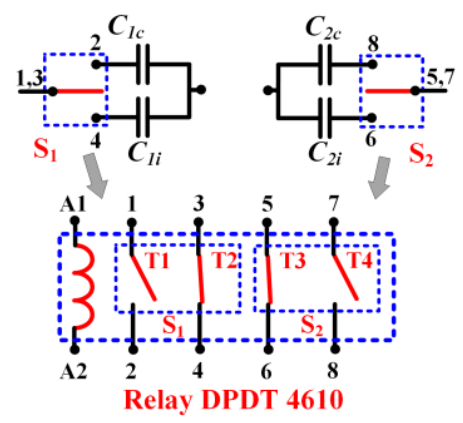

Fig. 15. The electrical schematic of switches $S_{1}$ and $S_{2}$ utilizing the DPDT relay.
TABLE IV

THE CONTROL SCHEME FOR SWITCHES $S_{1}$ AND $S_{2}$

\begin{tabular}{|c|c|c|c|c|c|}
\hline $\begin{array}{c}\text { Relay terminal } \\
\text { voltage } V_{\text {AlA2 }}\end{array}$ & $\mathrm{T} 1$ & $\mathrm{~T} 2$ & $\mathrm{~T} 3$ & $\mathrm{~T} 4$ & Mode \\
\hline $0 \mathrm{~V}$ & open & closed & closed & open & $\begin{array}{c}\text { Inductive } \\
\text { charging }\end{array}$ \\
\hline $12 \mathrm{~V}$ & closed & open & open & closed & $\begin{array}{c}\text { Conductive } \\
\text { charging }\end{array}$ \\
\hline
\end{tabular}

The experimental waveforms during the conductive mode are depicted in Fig. 16 for different load conditions. The resistance of the electronic load is varied from $45.3 \Omega$ to $254 \Omega$ during the test. To achieve the desired output voltage, $f_{i}$ is regulated between $100 \mathrm{kHz}$ and $135 \mathrm{kHz}$ for the four studied cases. As it can be seen from Fig. 16, the ZVS operation is achieved for the entire load range during the charging process.

The experimental waveforms of the inductive mode can be found in Fig. 17 during the CV mode with the perfect alignment conditions and a $400 \mathrm{~V} \mathrm{DC}$ input. As shown in Fig. 17(a), the phase shift value $\alpha$ is zero as the converter operates at the loadindependent output voltage at $f_{i}$. Moreover, the inverter output current $I_{\text {ini }}$ always leads the voltage $V_{\text {ini }}$, resulting in the ZVS operation in the CV mode. The current through the transmitter $I_{p}$ is shown in Fig. 17(b) while two receiver currents (e.g. $I_{1}$ and $I_{2}$ ) are presented in Fig. 17(c). As previously mentioned, the value difference between these two currents is small, therefore the circulating current in the on-board side is neglectable. Finally, Fig. 15(d) shows the voltages before the two rectifiers (e.g. $V_{1}$ and $V_{2}$ ) when $V_{o i}$ reaches $400 \mathrm{~V}$.

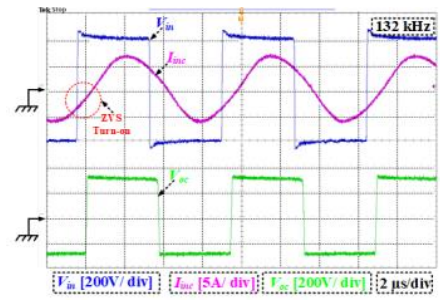

(a)

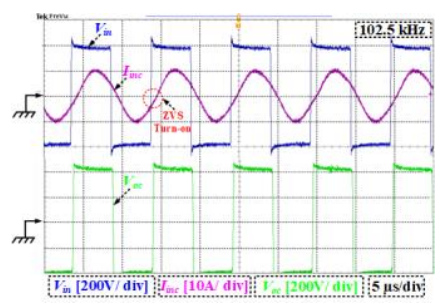

(c)

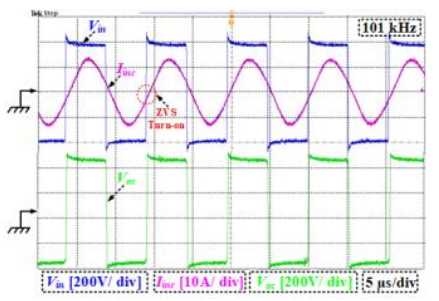

(b)

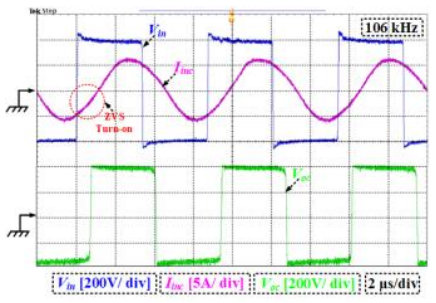

(d)
Fig. 16. Experimental waveforms in the conductive mode operation with $V_{\text {in }}=400 \mathrm{~V}$. (a) CC mode, $V_{o}=340 \mathrm{~V}, R_{o}=45 \Omega$. (b) CC mode, $V_{o}=400$ $\mathrm{V}, R_{o}=53.3 \Omega$. (c) CV mode, $I_{0}=5 \mathrm{~A}, R_{0}=80 \Omega$. (d) $\mathrm{CV}$ mode, $I_{o}=1.6$ A, $R_{0}=250 \Omega$.

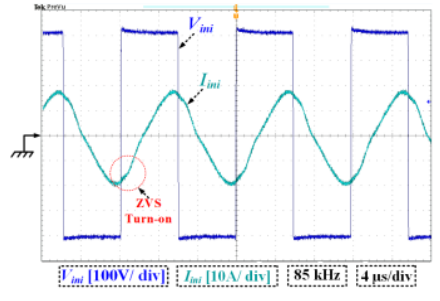

(a)

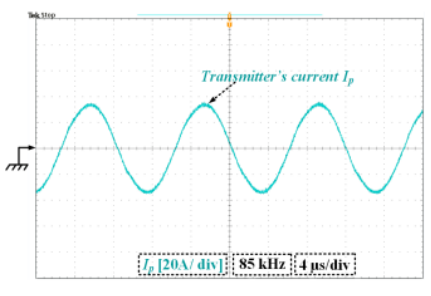

(b) 


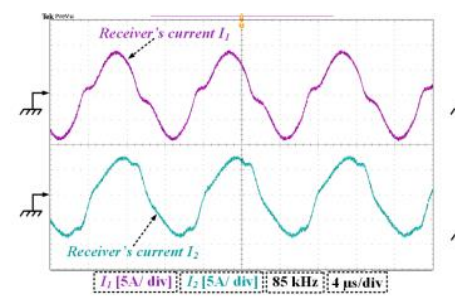

(c)

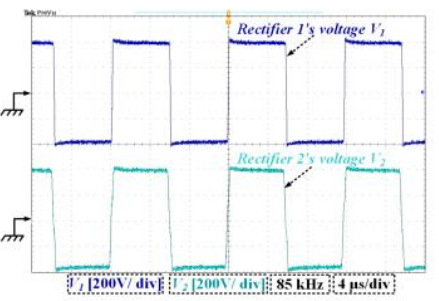

(d)
Fig. 17. Experimental waveforms in the inductive mode operation in the CV mode with $V_{\text {in }}=400 \mathrm{~V}, V_{o}=400 \mathrm{~V}, R_{o}=56.3 \Omega, \alpha=0^{\circ}$. (a) Inverter output's voltage and current, (b) the transmitter current, (c) the receivers' currents and (d) the rectifier input voltages.

In order to achieve ZVS operation for the entire load range in the inductive mode, the phase angle of the input impedance is required to be high as illustrated in Fig. 17 (a) (i.e. around 55 degrees). This increases the reactive power in the primary circuit. Several methods to minimize the input impedance's phase angle will be considered as our future works. These methods include adding an additional DC/DC converter between the rectifier and battery or utilizing the secondary controllable rectifier [19] for regulating the battery voltage. The idea behind these methods is to shift the output voltage control into the secondary side while the primary inverter operates at the low phase angle.

The performance of the proposed system in the inductive mode is further investigated under different misalignment conditions. The comparison between the experimental and simulation results of the DC output voltage $V_{o i}$ in the CV mode is shown in Fig. 18(a) in which $V_{o i}$ is reduced under misalignment operation. Under misalignment conditions of 0 $\mathrm{cm}, 10 \mathrm{~cm}$, and $20 \mathrm{~cm}$, the simulation value of $V_{o i}$ is $400 \mathrm{~V}, 380$ $\mathrm{V}$ and $310 \mathrm{~V}$, respectively. The experimental $V_{o i}$ is in a good agreement with the simulation value in general. However, the measured voltage is slightly different from the simulation results under the light load condition, which could be associated with the errors in tuning the resonant tank. Fig. 18(b) illustrates the system efficiency across a wide range of misalignment with the load resistance of $53.3 \Omega$. It is shown that the efficiency remains over $90 \%$ when the misalignment varies up to $15 \mathrm{~cm}$. Under the testing condition of $15-\mathrm{cm}$ air-gap and $30-\mathrm{cm}$ misalignment, the efficiency reaches $80.2 \%$.

Fig. 19(a) shows the measured efficiency of the hybrid charger at different equivalent battery loads over the $\mathrm{CC} / \mathrm{CV}$ charge profile. The converter maintains its efficiency higher than $93 \%$ in the conductive mode and $87 \%$ in the inductive mode over the entire load range. The efficiency data in the inductive mode is measured when the coils are fully aligned. The power loss on the contactor $S_{3}$ caused by the contact resistance is included in the measured efficiency, but its control circuit loss is excluded. The peak efficiencies at the rated power are $97.4 \%$ and $93.6 \%$ for the conductive $\left(\eta_{c}\right.$ in Fig. 19(b)) and inductive mode $\left(\eta_{i}\right.$ in Fig. 19(c)), respectively. All the efficiency measurements were conducted by the WT1600 power analyzer.

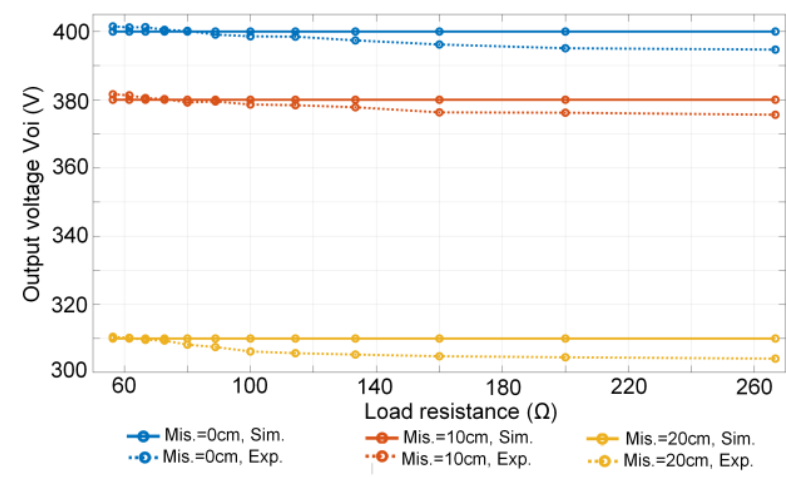

(a)

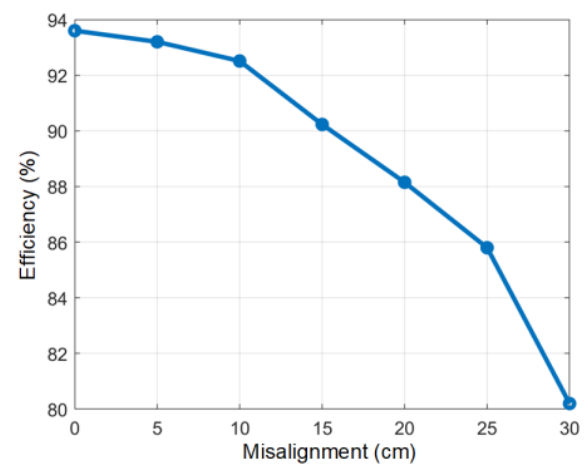

(b)

Fig. 18. (a) Comparison of the experimental and simulation results of $V_{o i}$ under misalignment operation in the inductive mode (CV mode, no control applied). (b) Measured efficiency under different lateral misalignments at the rated power $\left(R_{0}=53.3 \Omega\right)$.

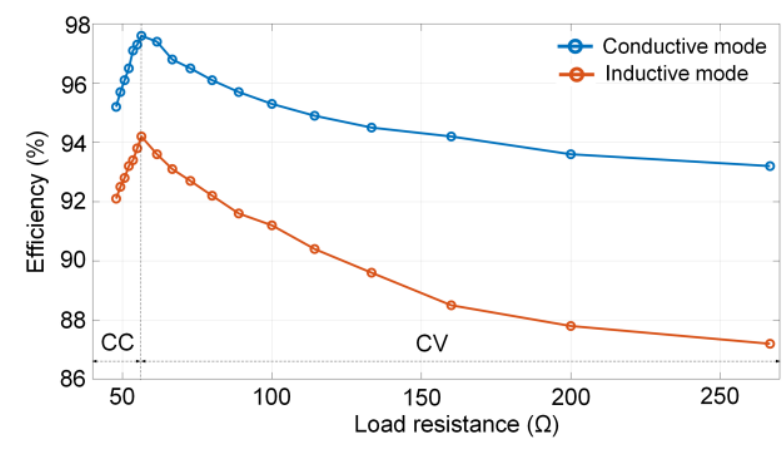

(a)

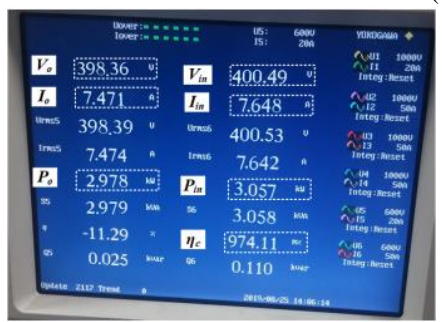

(b)

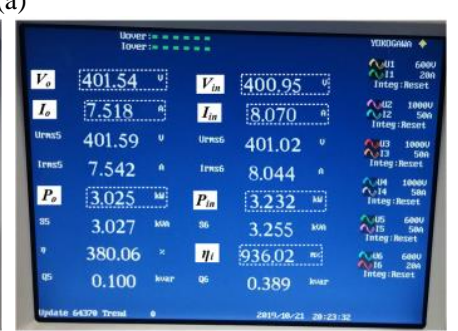

(c)
Fig. 19. (a) The measured efficiency in conductive mode and inductive modes (no misalignment) versus the equivalent battery load. Capture of efficiency from power meter at output power of $3 \mathrm{~kW}$ in (b) the conductive mode and, (c) the inductive mode. 


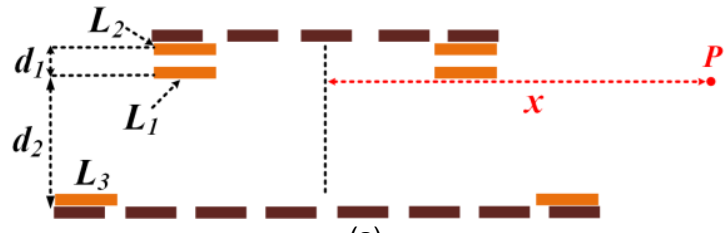

(a)

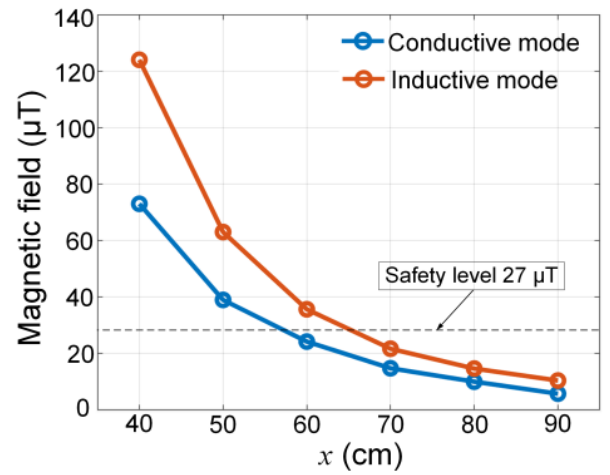

(b)

Fig. 20. Magnetic field measurement at different misalignment conditions (a) measurement setup, (b) measurement results.

Finally, in order to satisfy the ICNIRP exposure limits [28], the EMI surrounding the coupler coils are measured in each mode where the coils were aligned to charge at the rated power. The Gauss Meter SPECTRAN NF-5030 is used to measure EMI at the test point $P$ under different distances away from the coil's center $x$ as shown in Fig. 20 (a). The magnetic field strength is below $27 \mu \mathrm{T}$ starting from the positions $x$ of $60 \mathrm{~cm}$ and $70 \mathrm{~cm}$ in the conductive and inductive modes, respectively $(30 \mathrm{~cm}$ from the edge of the coupler). These magnitudes validate the simulation results in Section II. B and show its compliance with the EMI restrictions.

In order to demonstrate the benefits of the proposed system, a comparison with other similar hybrid charger systems [21, 22, $25,26]$ is carried out, which can be found in Table V. The first feature to consider is the location where power electronics components are shared. While [25-26] utilize the same offboard components in both modes, the on-board components are shared in [21-22] and this work. Please note that [21-22] only share the on-board DC/DC converter but not the magnetic components. This weakness is improved in this work by integrating the magnetic coils in the CM mode for the IM mode, which is not the case with other reported systems.

The next features are related to the design, implementation and control of the hybrid system for the battery charger with the charging profile. While the design parameter is missing in [2122], the system control strategy is not found in [22]. Although some of the above works [25-26] mentioned both design parameter and system control, none of them implements the battery charging profile of $\mathrm{CC} / \mathrm{CV}$ for the hybrid system, except this work.

Interestingly, the experimental verifications are only reported in [25] and this work. Although the output power is different for both, the proposed system achieves higher efficiencies in both modes, when tested at a full load condition.
TABLE V

COMPARISON OF VARIOUS HYBRID CHARGER SYSTEMS

\begin{tabular}{|c|c|c|c|c|c|}
\hline $\begin{array}{c}\text { Sharing } \\
\text { components }\end{array}$ & $\begin{array}{c}\text { On- } \\
\text { board }\end{array}$ & $\begin{array}{c}\text { On- } \\
\text { board }\end{array}$ & $\begin{array}{c}\text { Off- } \\
\text { board }\end{array}$ & $\begin{array}{c}\text { Off- } \\
\text { board }\end{array}$ & On-board \\
work \\
\hline $\begin{array}{c}\text { Magnetic } \\
\text { integration }\end{array}$ & No & No & No & No & Yes \\
\hline $\begin{array}{c}\text { Design } \\
\text { parameters }\end{array}$ & No & No & Yes & Yes & Yes \\
\hline $\begin{array}{c}\text { System } \\
\text { control }\end{array}$ & Yes & No & Yes & Yes & Yes \\
\hline $\begin{array}{c}\text { Implement } \\
\text { of CC-CV } \\
\text { charging }\end{array}$ & No & No & No & No & Yes \\
\hline $\begin{array}{c}\text { Practical } \\
\text { evaluation }\end{array}$ & No & No & Yes & No & Yes \\
\hline $\begin{array}{c}\text { Efficiency in } \\
\text { CM* }\end{array}$ & NA & NA & $87.63 \%$ & NA & $93-97.4 \%$ \\
\hline $\begin{array}{c}\text { Efficiency in } \\
\text { Na }\end{array}$ & NA & $88.25 \%$ & NA & $83.6 \%$ \\
\hline
\end{tabular}

Note: $* D C_{\text {in }}$-to- $D C_{\text {out }}$ efficiency

\section{CONCLUSION}

This paper presents a hybrid charger of inductive and conductive methods for electric vehicles. The advantage of the proposed systems is to maximize the sharing of the on-board power electronics and magnetic components between two charging modes. Consequently, the proposed hybrid charger reduces component counts and complexity of the system. To achieve this goal, a set of three coils is carefully designed to maximize the power transfer while complying with the restrictions of electromagnetic emissions. The proposed coupler coils along with the detailed design procedure are presented and discussed in the paper. The feasibility of the proposed charger is experimentally validated using a $3-\mathrm{kW}$ laboratory prototype, tested under different operating load conditions. The material presented in the paper lays a foundation for further studies of hybrid charger systems for EV applications.

\section{REFERENCES}

[1] M. Yilmaz and P. T. Krein, "Review of Battery Charger Topologies, Charging Power Levels, and Infrastructure for Plug-In Electric and Hybrid Vehicles," IEEE Trans. Power Electron., vol. 28, no. 5, pp. 21512169, May 2013.

[2] International Electrotechnical Commission, "IEC 61851-1:2017 Electric vehicle conductive charging system - Part 1: General requirements," Geneva, Switzerland, 2017.

[3] SAE International, "SAE J1772 - SAE Electric Vehicle and Plug in Hybrid Electric Vehicle Conductive Charge Coupler," Warrendale, USA, 2017.

[4] Mobility Foresights, "Global Electric Vehicle on Board Charger Market 2019-2025," 2020.

[5] S. S. Williamson, A. K. Rathore and F. Musavi, "Industrial Electronics for Electric Transportation: Current State-of-the-Art and Future 
Challenges," IEEE Trans. Ind. Electron., vol. 62, no. 5, pp. 3021-3032, May 2015.

[6] Z. U. Zahid, Z. M. Dalala, R. Chen, B. Chen and J. Lai, "Design of Bidirectional DC-DC Resonant Converter for Vehicle-to-Grid (V2G) Applications," IEEE Trans. Transport. Electrific., vol. 1, no. 3, pp. 232244, Oct. 2015.

[7] S. Kim and F. Kang, "Multifunctional Onboard Battery Charger for Plugin Electric Vehicles," IEEE Trans. Ind. Electron., vol. 62, no. 6, pp. 34603472, June 2015

[8] B. Lee, J. Kim, S. Kim and J. Lee, "A PWM SRT DC/DC Converter for 6.6-kW EV Onboard Charger," IEEE Trans. Ind. Electron., vol. 63, no. 2, pp. 894-902, Feb. 2016.

[9] W. Sun, Y. Xing, H. Wu and J. Ding, "Modified High-Efficiency LLC Converters with Two Split Resonant Branches for Wide Input-Voltage Range Applications," IEEE Trans. Power Electron., vol. 33, no. 9, pp. 7867-7879, Sept. 2018.

[10] H. Vu and W. Choi, "A Novel Dual Full-Bridge LLC Resonant Converter for CC and CV Charges of Batteries for Electric Vehicles," IEEE Trans. Ind. Electron., vol. 65, no. 3, pp. 2212-2225, Mar. 2018.

[11] K. Shi, D. Zhang and Y. Gu, "Interleaved Current-Driven Phase-Shift Full-Bridge Converter with Magnetic Integration and Voltage Doubler Rectifiers," IEEE Trans. Power Electron., vol. 33, no. 10, pp. 8308-8321, Oct. 2018.

[12] H. V. Nguyen, D. To and D. Lee, "Onboard Battery Chargers for Plug-in Electric Vehicles with Dual Functional Circuit for Low-Voltage Battery Charging and Active Power Decoupling," IEEE Access, vol. 6, pp. 7021270222,2018

[13] V. Vu, D. Tran and W. Choi, "Implementation of the Constant Current and Constant Voltage Charge of Inductive Power Transfer Systems With the Double-Sided LCC Compensation Topology for Electric Vehicle Battery Charge Applications," IEEE Trans. Power Electron., vol. 33, no. 9, pp. 7398-7410, Sept. 2018.

[14] F. Lu et al., "A Tightly Coupled Inductive Power Transfer System for Low-Voltage and High-Current Charging of Automatic Guided Vehicles," IEEE Trans. Ind. Electron., vol. 66, no. 9, pp. 6867-6875, Sept. 2019.

[15] A. Babu and B. George, "Sensor System to Aid the Vehicle Alignment for Inductive EV Chargers," IEEE Trans. Ind. Electron., vol. 66, no. 9, pp. 7338-7346, Sept. 2019.

[16] B. Zhang, Q. Chen, G. Ke, L. Xu, X. Ren and Z. Zhang, "Coil Positioning Based on DC Pre-excitation and Magnetic Sensing for Wireless EV Charging," IEEE Trans. Ind. Electron., April 2020.

[17] SAE International, "SAE J2954 - Wireless Power Transfer for Light-Duty Plug-in/Electric Vehicles and Alignment Methodology," Warrendale, USA, 2019.

[18] A. Triviño Cabrera, J. M. González and J. A. Aguado Sánchez, Wireless Power Transfer for Electric Vehicles: Foundations and Design Approach. Cham, Switzerland: Springer International Publishing, 2020.

[19] F. Corti et al., "A low-cost secondary-side controlled electric vehicle wireless charging system using a full-active rectifier," in Proc. 2018 Int. Conf. Elect. Electron. Technol. Autom., 2018, pp. 1-6.

[20] A. Khaligh and M. D'Antonio, "Global trends in high-power on-board chargers for electric vehicles," IEEE Trans. Veh. Technol., vol. 68, no. 4, pp. 3306-3324, Apr. 2019.

[21] S. Ichikawa, "Vehicle charging unit." European Patent EP2431214A1, Mar. 21, 2012.

[22] T. A. Nergaard and J. B. Straubel, "Integrated inductive and conductive electrical charging system.” U.S. Patent US8933661B2, Jan. 13, 2015.

[23] "Wireless in Action," Momentum Dynamics. Available online at: https://momentumdynamics.com/solution/\#autofleets (accessed July 20, 2020).

[24] O. C. Onar, M. Chinthavali, S. L. Campbell, L. E. Seiber and C. P. White, "Vehicular Integration of Wireless Power Transfer Systems and Hardware Interoperability Case Studies," IEEE Trans. Ind. Appl., vol. 55, no. 5, pp. 5223-5234, Sept.-Oct. 2019

[25] M. Chinthavali, O. C. Onar, S. L. Campbell and L. M. Tolbert, "Isolated wired and wireless battery charger with integrated boost converter for PEV applications," in Proc. IEEE Energy Convers. Congr. Expo. (ECCE), Montreal, QC, Sep. 2015, pp. 607-614.

[26] V. Berntsson, "Design and analysis of wireless charging combined with conductive charging," M. S. thesis, Chalmers University of Technology, Gothenburg, Sweden, 2017.

[27] V. Vu, M. Dahidah, V. Pickert and V. Phan, "A High-Power Multiphase Wireless Dynamic Charging System with low Output Power Pulsation for
Electric Vehicles," IEEE J. Emerg. Sel. Topics Power Electron., vol. 8, no. 4, pp. 3592 - 3608, Dec. 2020.

[28] ICNIRP Guidelines "Guidelines for limiting exposure to time-varying electric, magnetic and electromagnetic fields (1 Hz to $100 \mathrm{kHz})$," Health Phys., vol. 99, pp. 818-836, 2010.

[29] A. A. S. Mohamed, A. Meintz, P. Schrafel and A. Calabro, "Testing and Assessment of EMFs and Touch Currents From 25-kW IPT System for Medium-Duty EVs," IEEE Trans. Veh. Technol., vol. 68, no. 8, pp. 74777487, Aug. 2019.

[30] R. W. Erickson and D. Maksimovic, Fundamentals of Power Electronics, 2nd ed. New York, NY, USA: Academic, 2001.

[31] G. J. Capella, J. Pou, S. Ceballos, J. Zaragoza and V. G. Agelidis, "Current-Balancing Technique for Interleaved Voltage Source Inverters With Magnetically Coupled Legs Connected in Parallel," IEEE Trans. Ind. Electron., vol. 62, no. 3, pp. 1335-1344, March 2015.

[32] S. Augustine, M. K. Mishra and N. Lakshminarasamma, "Adaptive Droop Control Strategy for Load Sharing and Circulating Current Minimization in Low-Voltage Standalone DC Microgrid," IEEE Trans. Sustain. Energy., vol. 6, no. 1, pp. 132-141, Jan. 2015.

[33] M. Shirk and J. Wishart, "Effects of electric vehicle fast charging on battery life and vehicle performance," SAE Tech. Paper 2015-01-1190, 2015.

[34] B. Zhang, Q. Chen, G. Ke, L. Xu, X. Ren and Z. Zhang, "Coil Positioning Based on DC Pre-excitation and Magnetic Sensing for Wireless EV Charging," IEEE Trans. Ind. Electron., April 2020.

[35] X. Qu et al., "Wide Design Range of Constant Output Current Using Double-Sided LC Compensation Circuits for Inductive-Power-Transfer Applications," IEEE Trans. Power Electron., vol. 34, no. 3, pp. 23642374, March 2019.

[36] Colonel Wm. T. McLyman, Transformer and Inductor Design Handbook, 3rd ed. Boca Raton, FL, USA: CRC Press, 2004.

[37] KEMET, "Polypropylene Pulse/High Frequency Capacitors R76H, $125^{\circ} \mathrm{C}$ Double Metallized Polypropylene Film," July, 2019. Available online: https://content.kemet.com/datasheets/KEM_F3118_R76H.pdf.

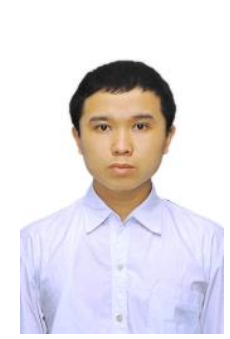

Van-Binh Vu (S'17) received the bachelor degree (talented program) from the Hanoi University of Science and Technology, Hanoi, Vietnam, in 2014, the Master degree from Soongsil University, Seoul, Republic of Korea in 2016, and the PhD degree from Newcastle University, Newcastle upon Tyne, UK, in 2020 all in Electrical Engineering. His main research areas include the fields of power electronics, especially on wireless power transfer for electric vehicles.

Dr. Vu has published in the top-tier IEEE journals in power electronics such as the IEEE Transactions on Industrial Electronics, the IEEE Transactions on Power Electronics and the IEEE Journal of Emerging and Selected Topics in Power Electronics. He been awarded a travel grant from IEEE Industrial Electronics Society to attend the 26th IEEE International Symposium on Industrial Electronics and has served as a regular reviewer for both IEEE and IET journals.

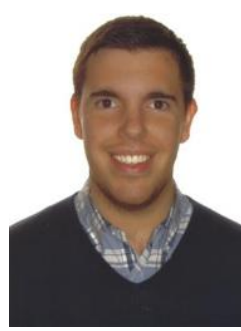

Jose M. González-González (M'15) was born in Málaga, Spain. He received the M. degree (major power systems) in industrial engineering from University of Málaga, Spain in 2015.

$\mathrm{He}$ is currently working towards his Ph.D. on wireless power transfer in electric vehicles, focused on the design of a prototype with bidirectional features. $\mathrm{He}$ also has practical experience working on smart grids and renewable energy projects, with some publications on the integration of battery energy storage. 


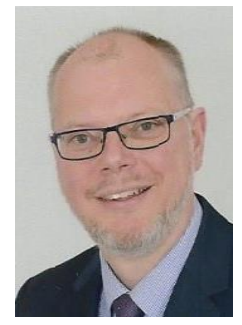

Volker Pickert (M'04) studied at the RWTH Aachen, Germany, and Cambridge University, UK, and he received his Dipl.-Ing. degree in Electrical and Electronic Engineering from RWTH Aachen in 1994. He was awarded the Ph.D. degree in power electronics from Newcastle University, Newcastle upon Tyne, U.K., in 1997. From 1998 to 1999, he was an Application Engineer with Semikron $\mathrm{GmbH}$, Nuremberg, Germany, and from 1999 to 2003 he was a Group Leader at Volkswagen AG, Wolfsburg, Germany, responsible for the development of electric drives for electric vehicles.

In 2003, he was appointed as a Senior Lecturer in the Electrical Power Group, Newcastle University, and in 2011 he became a Full Professor of Power Electronics. In 2012, he became the Head of the Electrical Power Group and in 2020 he became the Director of Discipline for Electrical and Electronic Engineering. He has published more than 180 book chapters, journal articles, and conference papers in the area of power electronics and electric drives. His current research interests include power electronics for transport applications, thermal management, health monitoring techniques, and advanced nonlinear control. Prof. Pickert received the IMarEST Denny Medal for the best article in the Journal of Marine Engineering in 2011 and in 2018 he received the Best Paper Award at IEEE International Conference on Computing Electronics \& Communications Engineering (iCCECE), Essex, UK. He is regularly invited as keynote speaker and advises various governments on energy and transport related issues. In 2019 he became the Director of UK's EPSRC Doctoral Training Centre in Power Electronics for Sustainable Electric Propulsion. $\mathrm{He}$ is the active Editorin-Chief of the IET Power Electronics journal.

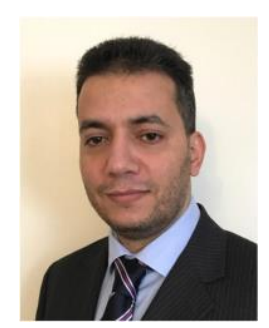

Mohamed Dahidah (M'02-SM'10) received the Ph.D. degree in electrical engineering from Multimedia University, Malaysia, in 2008. Dr Dahidah was an Assistant Professor in the Department of Electrical and Electronic Engineering, The University of Nottingham, Malaysia Campus, till November 2012. He is currently a Senior Lecturer with the School of Engineering, Newcastle University, Newcastle Upon Tyne, U.K.

Dr Dahidah is the recipient of Frist prize paper award at IEEE Conference on Sustainable Utilization and Development in Engineering and Technology, Kuala Lumpur, Malaysia, 2010 and Girling Watson Fellowship Award, the University of Sydney, Australia, 2009. He has authored or co-authored over 80 refereed journal and conference papers in the field of power electronics. His current research interests include modular power converters, battery charger for EVs, solid state transformers and advanced power conversion for renewable energy integration.

Dr. Dahidah is the Deputy Editor-in-Chief for IET Power Electronics and has been a regular reviewer for both IEEE and IET journals.

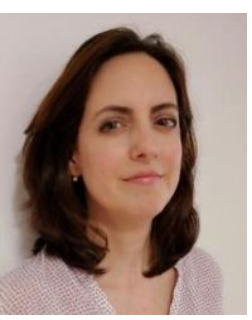

Alicia Triviño $\left(S^{\prime} 17\right)$ is a Telecommunication Engineer (2002) and a Computer Science Engineer (2008) by the University of Málaga (Spain). Her Thesis, which was defended in 2007, focused on wireless networks. In 2010, she started teaching at the University of Málaga where she currently holds a position as an Associate Professor.

Since 2011, her research activities focus on wireless power transfer. In the area related to Electric Vehicles, she has actively participated in the design and development of wireless charger prototypes, which include relevant features such as bi-directionality and dynamic charge. As a result, she has authored several papers in indexed journals and edited two books. She has also an extensive experience on the review of research works on this topic in international conferences and prestigious journals. 